\title{
Tatipirun e a fuga de um menino pelado
}

Elizabeth Ramos

Resumo: Em 1937, o livro 'A terra dos meninos pelados' venceu o prêmio de literatura infantil do Ministério da Cultura, trazendo à cena literária juvenil um romancista já consagrado na literatura de adultos: Graciliano Ramos. No livro, o leitor é transportado a Tatipirum, o universo em que Raimundo não é mais o Outro, o diferente. Lá habitam meninos que também têm um olho azul e outro preto, e também são carecas. Em Tatipirum é natural ser diferente. Com uma linguagem divertida e leve, Graciliano apresenta ao jovem leitor reflexões relevantes sobre temas como a diferença, a diversidade e a tolerância.

Palavras-chave: Graciliano Ramos, A terra dos meninos pelados, tradução, inglês.

Em janeiro de 1937, Graciliano Ramos foi libertado, após um período de onze meses de prisão política no Rio de Janeiro. Em fevereiro, sua mulher, Heloisa, voltou a Maceió, para providenciar a mudança e buscar as filhas, permitindo, assim, que a família fixasse residência na então Capital Federal. Ao voltar do cais, onde embarcara Heloísa, o Velho Graça escreveu em carta endereçada a ela: "Conte a Tatá1 a história dos meninos pelados. Diga-me qual é a opinião dele". (RAMOS, 1981: 169) Em carta seguinte, com data de 14 de fevereiro, Graciliano comenta: "Apenas acabei de emendar os meninos pelados, que não sei se prestam. Vi hoje uns desenhos admiráveis que o Santa ${ }^{2}$ vai mandar para o mesmo concurso de coisas infantis. Os meus meninos não valem nada diante das figuras do nosso amigo, um circo de cavalinhos formidável. Formidável." (RAMOS, 1981: 169) Ao final da carta, acrescenta: "Bem d. Ló, agora vou escrever ao Aurélio e depois ler os meninos pelados".

Tatá era o apelido de Ricardo Ramos, filho de Graciliano, então com 8 anos.

2 Santa Rosa, ilustrador de vários livros de Graciliano Ramos. 
Em maio do mesmo ano, a história $A$ terra dos meninos pelados, recebia o prêmio de Literatura Infantil do Ministério da Educação para o qual o escritor havia concorrido, utilizando pseudônimo. Graciliano Ramos, escritor já reconhecido no território da literatura brasileira para adultos, tornava-se, então, premiado num "concurso de coisas infantis".

No livro, o jovem leitor encontra a história de Raimundo, um menino diferente: tinha a cabeça pelada, um olho azul e outro preto. Por não ser igual aos outros meninos, Raimundo era motivo de zombaria por parte das outras crianças, não tinha amigos, e nem com quem conversar. Por isso, falava sozinho, construindo na sua cabeça de menino um lugar encantado, onde as crianças tinham a cabeça pelada, um olho azul, outro preto e recebiam das laranjeiras frutas frescas ofertadas com delicadeza. Em Tatipirun, terra imaginária para onde Raimundo foge da dor imposta pela diferença, as cigarras cantavam em "enormes discos de vitrola" que rodopiavam no ar, os carros não atropelavam ninguém, não fazia calor nem frio, não havia noite, não chovia, as margens do rio se fechavam para que se pudesse cruzá-lo, ninguém envelhecia, e todos os caminhos eram certos.

Não pense o leitor, no entanto, que, por serem todas carecas e terem olhos de cores diferentes, as crianças de Tatipirun fossem iguais. Nem seria bom que fossem, pois "gente não é rapadura", como disse Raimundo ao menino sardento (p. 48). Eram alvos, negros, altos, baixos, meninos e meninas, que se vestiam de maneira diferente de Raimundo. Andavam descalços e usavam túnicas multicores de seda fabricada pelas aranhas. Aranhas vermelhas, que se balançavam em teias brancas, azuis, amarelas, verdes, roxas, cor das nuvens do céu e do fundo do mar. Tatipirun era uma terra de diferenças, onde habitavam crianças como Pirenco, Talima, Sira, um menino-anão e Caralâmpia, a menina que virou princesa, porque tinha jeito de princesa, tinha a cabeça enfeitada de rosas, os braços ornados com pulseiras de cobra coral, trazia no peito um broche de vaga-lume e, na lembrança, notícia de outras terras.

Andei numa terra diferente das outras, uma terra onde as árvores crescem com as folhas para baixo e as raízes para cima. As aranhas são do tamanho de gente, e as pessoas do tamanho de aranhas. [...] Os guris que eu vi têm duas cabeças, cada uma com quatro olhos, dois na frente e dois atrás. (p. 65)

$\mathrm{Na}$ contramão da intolerância, em $A$ terra dos meninos pelados, Graciliano Ramos abre a possibilidade de reflexão, junto ao público-leitor 
infantojuvenil, sobre a pluralidade do mundo nas suas feições, visões, hábitos, crenças. "Por que é que não existem pessoas diferentes de nós? Se há criaturas com duas pernas e uma cabeça, pode haver outras com duas cabeças e uma perna" (p. 68). Apresenta, ainda, a importância da delicadeza e o conforto do acolhimento, sem mencionar outras leituras possíveis, para além do universo infantojuvenil, de conteúdo ideológico, próprio da época em que a história foi escrita. Tais características tornam importante a tradução da obra para jovens falantes de outras línguas.

No caso do inglês, a tradução de A terra dos meninos pelados não impõe grandes dificuldades ao tradutor, exceto com relação a alguns termos culturais específicos, como é o caso do próprio título da história. A expressão "meninos pelados", por exemplo, não se refere a crianças desnudas, como a princípio pode parecer. Refere-se ao fato de serem todas carecas. Na tradução para a língua inglesa, minha escolha do termo "bald" dirime a dúvida de quem se depara com o título pela primeira vez, não significando, evidentemente, que a opção seja melhor do que o título em português. Ao longo da tradução, considerei importante, ainda, atualizar algumas expressões datadas, como "discos de vitrola", no sentido de aproximar a história do universo dos jovens leitores do século XXI.

Dada a limitação de espaço, optei por traduzir os quatro primeiros capítulos da história. Julgo que dão uma idéia inicial sobre o conteúdo do livro, que venho traduzindo integralmente, para futura publicação. Seguem, então, minhas soluções, acrescidas de alguns poucos comentários.

\begin{tabular}{|c|c|}
\hline A terra dos meninos pelados & The land of bald kids \\
\hline $\begin{array}{l}\text { Havia um menino diferente dos outros } \\
\text { meninos. Tinha o olho direito preto, o } \\
\text { esquerdo azul e a cabeça pelada. Os } \\
\text { vizinhos mangavam dele e gritavam: } \\
\text { - Ó pelado! } \\
\text { Tanto gritaram que ele se acostumou, } \\
\text { achou o apelido certo, deu para se } \\
\text { assinar a carvão, nas paredes: dr. } \\
\text { Raimundo Pelado. Era de bom gênio e não } \\
\text { se zangava; mas os garotos dos } \\
\text { arredores fugiam ao vê-lo, escondiam-se }\end{array}$ & $\begin{array}{l}\text { There was a boy who was different from } \\
\text { the other boys. His right eye was black, } \\
\text { his left eye was blue, and his head was } \\
\text { bald. The neighbors mocked him, } \\
\text { shouting: } \\
\text { - Hey, baldy! } \\
\text { And so much did they shout that he got } \\
\text { used to the mockery, and got used to } \\
\text { the nickname. He even started signing } \\
\text { his name in charcoal on the walls as Dr. } \\
\text { Raimundo the Bald. He was good-natured }\end{array}$ \\
\hline
\end{tabular}




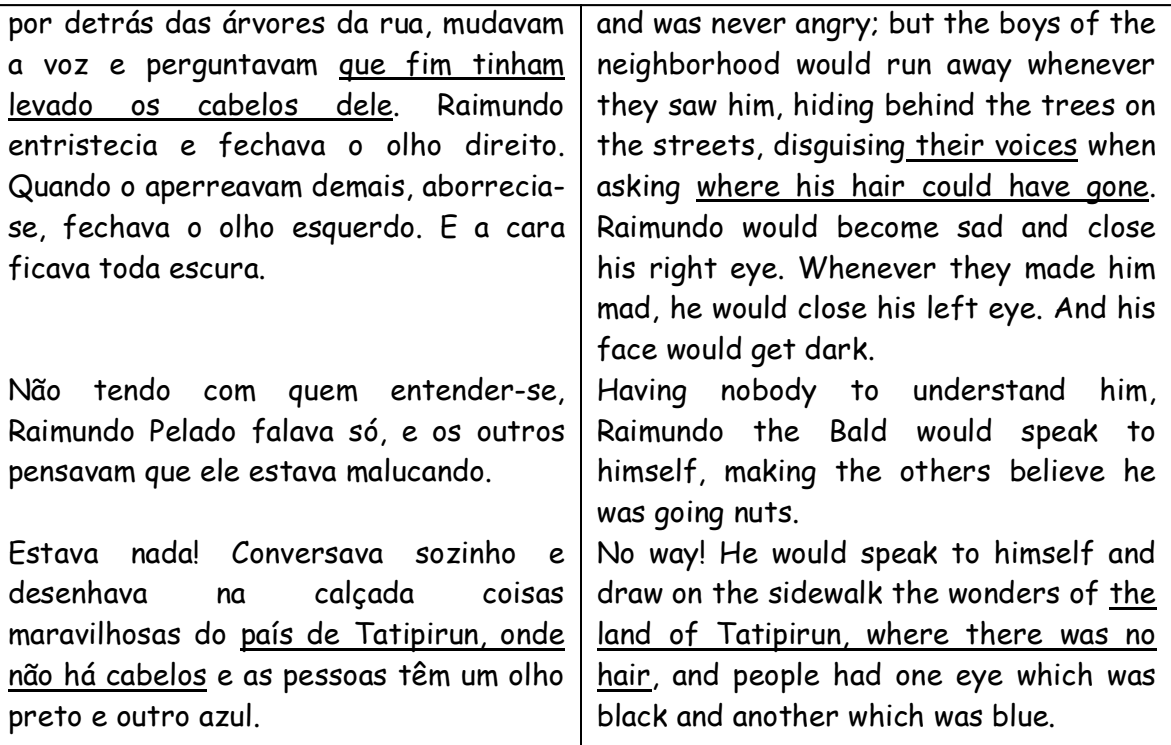

Uma vez resolvida a tradução de "pelados" para "bald", o título gera mais uma dúvida. Seriam carecas apenas os meninos? O final do primeiro capítulo, no entanto, resolve a dúvida, trazendo a informação de que Tatipirum é um país onde não há cabelos. Sendo assim, o termo "meninos" foi generalizado em "kids". A expressão "mudar a voz" foi expandida para "disguising their voices", pois, de fato, é o que ocorre quando meninos gritam, zombando de alguém. Além disso, há que se notar a expressão "que fim tinham levado os cabelos dele" traduzida, simplesmente, por "where his hair could have gone".

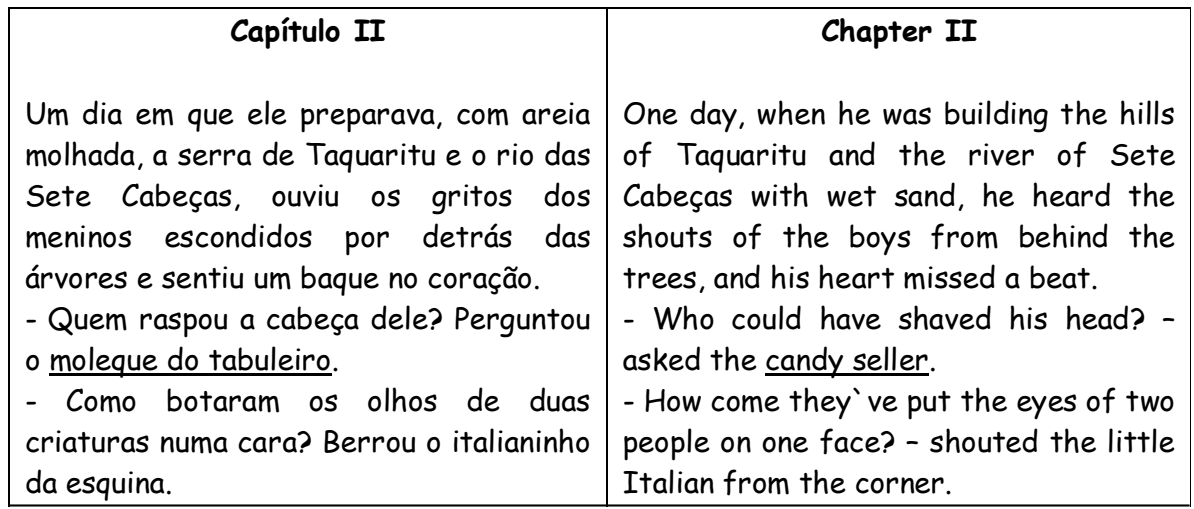




\begin{tabular}{|c|c|}
\hline $\begin{array}{l}\text { - Era melhor que me deixassem quieto, } \\
\text { disse Raimundo baixinho. } \\
\text { Encolheu-se e fechou o olho direito. Em } \\
\text { seguida, foi fechando o olho esquerdo, } \\
\text { não enxergou mais a rua. As vozes dos } \\
\text { moleques desapareceram, só se ouvia a } \\
\text { cantiga das cigarras. Afinal as cigarras } \\
\text { se calaram. } \\
\text { Raimundo levantou-se, entrou em casa, } \\
\text { atravessou o quintal e ganhou o morro. Aí } \\
\text { começaram a surgir as coisas estranhas } \\
\text { que há na terra de Tatipirun, coisas que } \\
\text { ele tinha adivinhado, mas nunca tinha } \\
\text { visto. Sentiu uma grande surpresa ao } \\
\text { notar que Tatipirun ficava ali perto de } \\
\text { casa. Foi andando na ladeira, mas não } \\
\text { precisava subir: enquanto caminhava, o } \\
\text { monte ia baixando, baixando, aplanava-se } \\
\text { como uma folha de papel. E o caminho, } \\
\text { cheio de curvas, estirava-se como uma } \\
\text { linha. Depois que ele passava, a ladeira } \\
\text { tornava a empinar-se e a estrada se } \\
\text { enchia de voltas novamente. }\end{array}$ & $\begin{array}{l}\text { - You'd better leave me alone - said } \\
\text { Raimundo softly. } \\
\text { He shrank and closed his right eye. } \\
\text { Immediately afterwards, he closed his } \\
\text { left eye, and was unable to see the } \\
\text { street any longer. The boys' voices then } \\
\text { disappeared, and only the cicadas' songs } \\
\text { could be heard. Then they became } \\
\text { silent. } \\
\text { Raimundo got up, went into the house, } \\
\text { crossed the backyard, and reached the } \\
\text { hill. Then, the strange things of the } \\
\text { land of Tatipirun began to appear. } \\
\text { Things he had only supposed to exist, } \\
\text { but he had never seen. He was quite } \\
\text { surprised to notice that Tatipirun was } \\
\text { right there, by his house. He started } \\
\text { climbing the hill, but noticed he did not } \\
\text { have to make an effort to climb: as he } \\
\text { walked, the hill would start to become } \\
\text { flat, just like a sheet of paper. As soon } \\
\text { as he went ahead, the hill would steepen } \\
\text { again, and the road would be back with } \\
\text { all its bends. }\end{array}$ \\
\hline
\end{tabular}

O segundo capítulo traz alguns itens culturais específicos do tempo e do lugar de fala do escritor, tais como "moleque do tabuleiro". Optei por traduzir o moleque do tabuleiro por "candy seller", uma vez que houve um tempo em que se vendiam balas em tabuleiros pendurados no pescoço de meninos ou homens mais velhos, particularmente, na porta dos cinemas. $A$ tradução de "moleque" por "boy" neutraliza o termo, deixando-o livre do possivel aspecto pejorativo que a palavra "moleque" tem em alguns lugares do Brasil. Ao final do capítulo, o texto de partida faz referência ao fato de que Raimundo "não precisava subir", levando o leitor a concluir que não havia necessidade de esforço físico. Assim, explicitei o fato com "he did not have to make an effort to climb". Da mesma forma, quando no início do capítulo Graciliano usa o termo "preparar, com areia molhada, a serra de Taquaritu e o rio das Sete Cabeças", optei pelo uso de "build", esclarecendo a ação de Raimundo.

Um dos conhecidos traços da escrita de Graciliano Ramos é a concisão construída através da eliminação de "que", " $e$ ", e outras conjunções e 
preposições. No quinto parágrafo, no entanto, acrescentei "and" para tornar mais fluida a leitura em inglês.

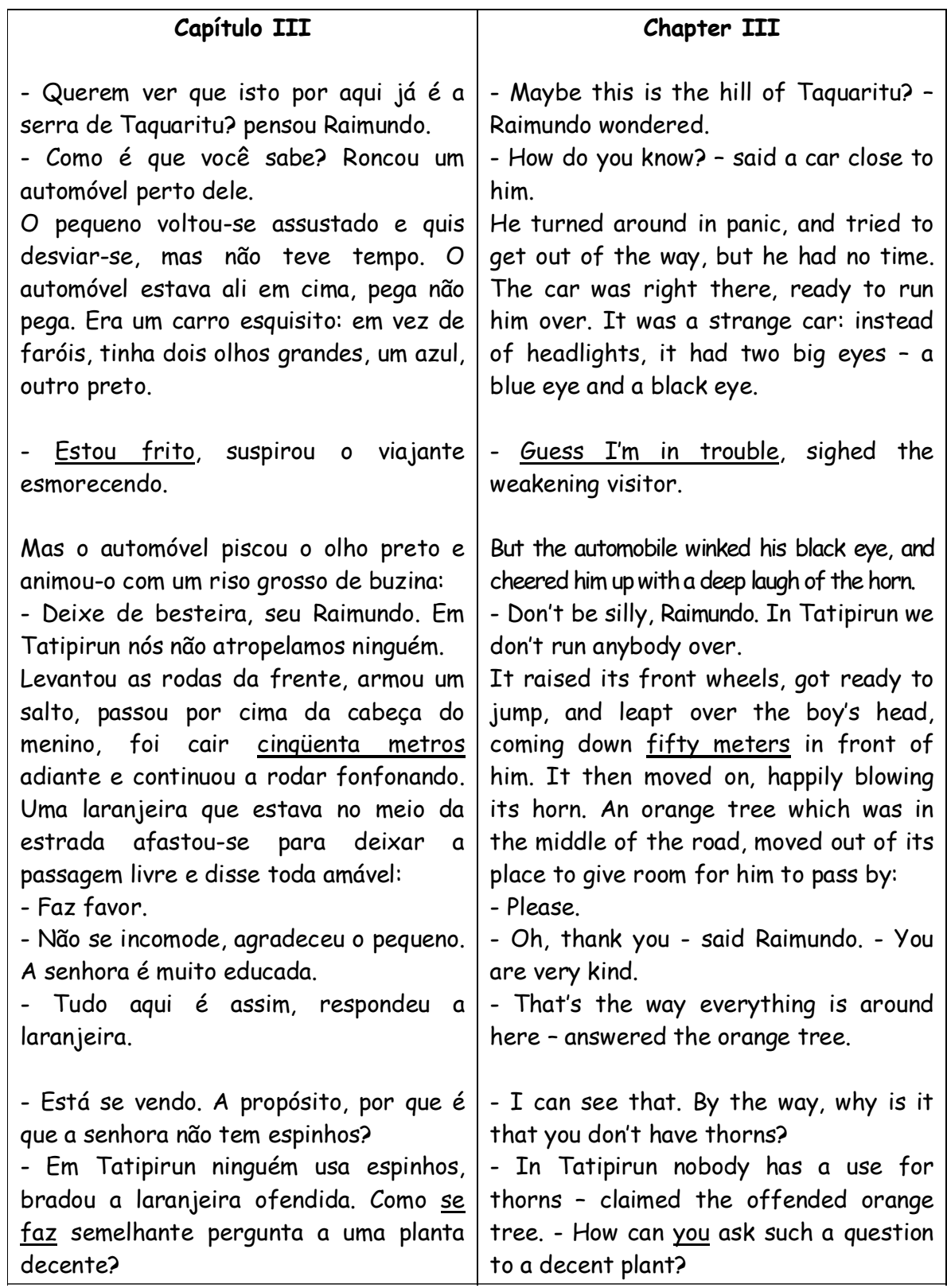




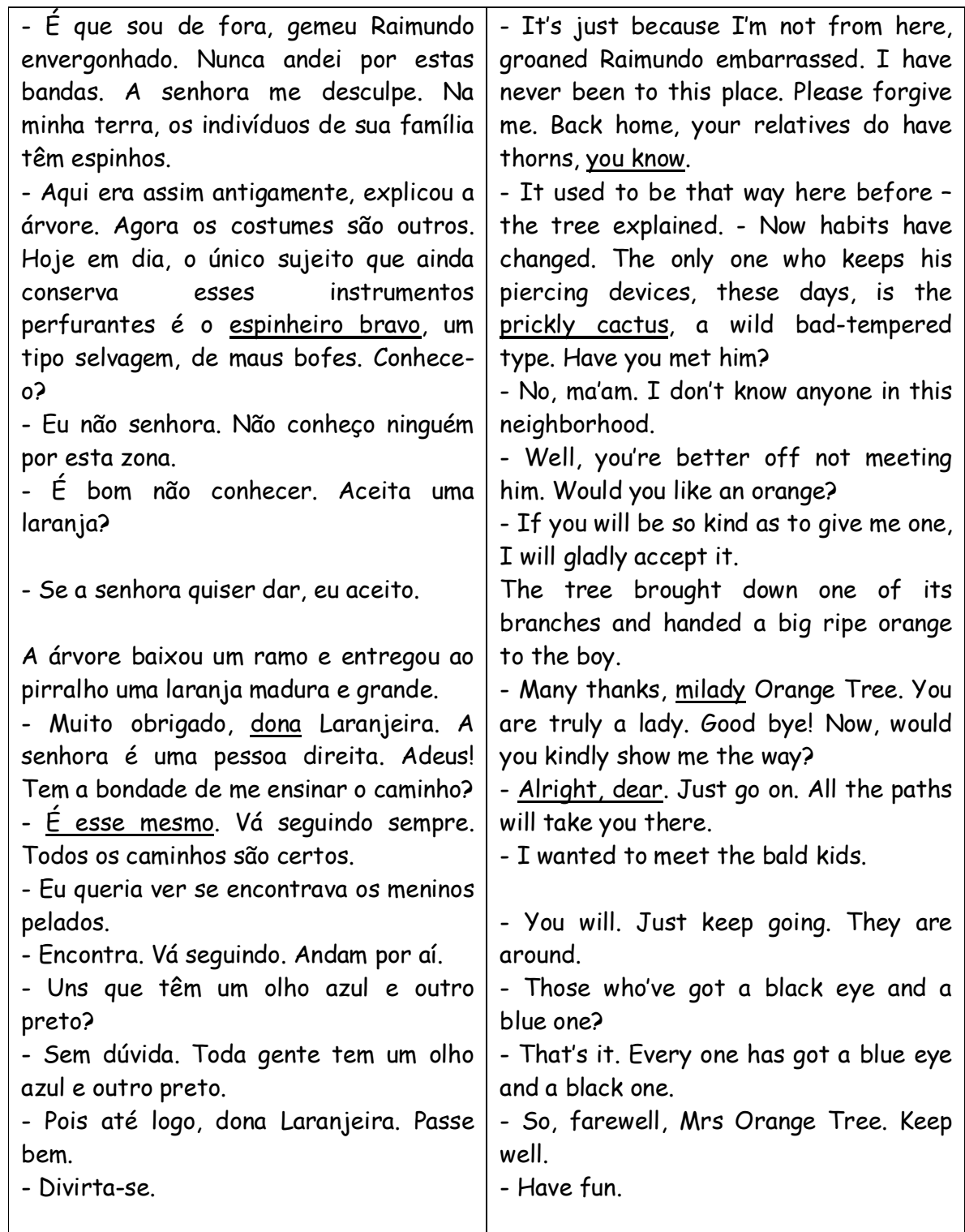

No capítulo III, o espinheiro bravo, planta da caatinga do nordeste brasileiro, foi generalizada na tradução prickly cactus, para ajudar a construção das imagens na imaginação dos jovens leitores. Uma boa ilustração pode mostrar o tipo de cacto a que a história se refere. A expressão 
"estou frito" perdeu a carga cultural, transformando-se em "guess I'm in trouble".

$O$ acréscimo de "you know" foi escolhido no sentido de garantir o tom coloquial do diálogo entre Raimundo e a laranjeira, mais uma vez num movimento contrário aos enxugamentos que Graciliano Ramos fazia ao escrever. No mesmo rastro de escolhas, traduzi "é esse mesmo" por alright, dear, para reforçar o tom de amabilidade, de diferença de idade e de posição entre Raimundo e a laranjeira.

\begin{tabular}{|c|c|}
\hline Capítulo IV & Chapter IV \\
\hline $\begin{array}{l}\text { Raimundo continuou a caminhada, } \\
\text { chupando a laranja e escutando as } \\
\text { cigarras, umas cigarras graúdas que } \\
\text { passeavam sobre discos de vitrola } \\
\text { enormes. Os discos giravam, soltos no ar, } \\
\text { as cigarras não descansavam - e havia em } \\
\text { toda a parte músicas estranhas, como } \\
\text { nunca ninguém ouviu. Aranhas vermelhas } \\
\text { balançavam-se em teias que se estendiam } \\
\text { entre os galhos, teias brancas, azuis, } \\
\text { amarelas, verdes, roxas, cor das nuvens } \\
\text { do céu e cor do fundo do mar. Aranhas } \\
\text { em quantidade. Os discos moviam-se, } \\
\text { sombras redondas projetavam-se no } \\
\text { chão, as teias agitavam-se como redes. }\end{array}$ & $\begin{array}{l}\text { Raimundo went on walking, eating his } \\
\text { orange and listening to the cicadas. Nice } \\
\text { big cicadas which rode about on huge } \\
\text { CDs. The CDs turned, free in the open } \\
\text { air, and the cicadas didn't rest - there } \\
\text { was all around the sound of strange } \\
\text { music, the kind no one had ever heard. } \\
\text { Red spiders swung on webs which hung } \\
\text { between twigs, white, blue, yellow, } \\
\text { green, purple webs, and also those with } \\
\text { the color of the sky and the bottom of } \\
\text { the sea. Spiders galore. The CDs moved, } \\
\text { projecting round shadows onto the } \\
\text { ground, the webs swung as if they were } \\
\text { hammocks. }\end{array}$ \\
\hline $\begin{array}{l}\text { Raimundo deixou a serra de Taquaritu e } \\
\text { chegou à beira do rio das Sete Cabeças, } \\
\text { onde se reuniam os meninos pelados, bem } \\
\text { uns quinhentos, alvos e escuros, grandes } \\
\text { e pequenos, muito diferentes uns dos } \\
\text { outros. Mas todos eram absolutamente } \\
\text { calvos, tinham um olho preto e outro azul. }\end{array}$ & $\begin{array}{l}\text { Raimundo left the hills of Taquaritu } \\
\text { behind, and reached the Sete Cabeças } \\
\text { river, where the bald kids gathered, in a } \\
\text { bunch of about five hundred, white and } \\
\text { dark ones, tall and short, very different } \\
\text { from one another. But they were all } \\
\text { totally bald, and had one eye which was } \\
\text { black and another which was blue. }\end{array}$ \\
\hline
\end{tabular}

Como já esclarecido, decidi atualizar o termo "discos de vitrola" por "CDs", para estimular a imaginação do jovem leitor dos nossos dias, aproximando-o da história. A expressão "passeavam sobre enormes discos de vitrola" gerou dificuldade na tradução. Optei por rode about por entender que a expressão contempla a atmosfera de prazer construída nesse tre- 
cho da história, embora não deixe clara a idéia de que ao passearem sobre os discos, produziam o som.

A seleção dos trechos, que constituem o corpus de análise da tradução aqui apresentada, não foi tarefa fácil, dada a riqueza oferecida por $A$ terra dos meninos pelados ao imaginário do leitor. A opção pela preservação da linearidade dos capítulos pareceu, pois, a mais lógica, embora não tenha resolvido a minha frustração por não poder apresentar a tradução dos vinte e três capítulos que compõem o texto completo de Graciliano Ramos, uma história rica em reflexões sobre a importância do respeito às diferenças humanas, contra a intolerância, num mundo tão diverso como o que vivemos.

Além de ter sido traduzida para o alemão, sob o título Raimundo im Land Tatipirún, A terra dos meninos pelados foi traduzida intersemioticamente, em 2003, pela Rede Globo de televisão, em formato de minissérie adaptada por Claudio Lobato e Márcio Trigo. É interessante observar que Herval Silveira, menino de 11 anos, escolhido para interpretar Raimundo, apesar de feliz por ter sido escalado para o papel, sentiu-se incomodado ao saber que teria de raspar o cabelo e as sobrancelhas e usar uma lente de contato no olho direito. Lembrou-se dos seus dias de Raimundo, quando enfrentava os apelidos de "salva-vidas de aquário", "pintor de rodapé" e "segurança de formigueiro", por ser mais baixo que os amigos da rua. "Nunca gostei de apelidos. Mas o que eu podia fazer? Brigar não resolve nada..." afirmou conformado.

As diferentes traduções confirmam a importância da temática levantada por Graciliano Ramos em $A$ terra dos meninos pelados, pois ao contrário do que pensa o menino sardento, não seria bom que fosse todo mundo igual. Afinal, a gente não é rapadura.

Feitos os comentários técnicos sobre a tradução, cabe agora o relato confessional.

Em Retrato Fragmentado, Ricardo Ramos, filho de Graciliano, comenta sobre o avô Sebastião, afirmando que praticamente não o conheceu. Dele guardava como lembrança "retratos, alusões, em particular diálogos com meu pai". (RAMOS, 1992, p. 23)

Também para mim, a imagem de meu avô Graciliano Ramos está nas fotografias - duas delas em que aparecemos juntos; nos seus livros sobre

3 http://diversao.terra.com.br/gente/noticias/0,OI3523761-EI13419,00Serie+A+Terra+dos+ Meninos+ Pelados +estreia+dia.html 
os quais, não raro, me detenho, para lhes admirar a escrita; nas histórias que meu pai, meus tios, minha avó sempre me contaram e repetiram. Assim, ao traduzir o Velho Graça, todas essas imagens se confundem, e a tarefa se torna mais árdua. Se por um lado sou tomada da imensa angústia de um débito impossível de ser saldado, sou também possuída pelo contentamento em poder resgatar uma parcela da sua memória. Se por um lado sinto-me mais próxima do meu autor favorito, por outro, afasto-me do pai de meu pai. No processo, o movimento é incessante. Tradutora e autor convergem e se fundem não apenas geneticamente. Em outros momentos, afastam-se. Difícil dizer onde termina o avô e começa o autor.

$\mathrm{Na}$ tradução fragmentada do texto de Graciliano Ramos, o leitor encontrará, pois, o resultado de um complexo movimento entre semelhanças e diferenças, como de resto ocorre em qualquer processo tradutório.

\section{Agradecimento:}

Agradeço a cuidadosa revisão do texto traduzido feita por John Milton.

\section{Referências}

RAMOS, Graciliano. A terra dos meninos pelados. $34^{a}$. Edição. Ilustrações: Roger Mello, cedidas pela Verlag Nagel \& Kimche AG, Zurick-Frauenfeld, 1996. Rio de Janeiro: Record, 2006.

Cartas. Rio de Janeiro: Record, 1981.

RAMOS, Ricardo. Graciliano: retrato fragmentado. São Paulo: Siciliano, 1992. 